\title{
Smoking-related changes in DNA methylation and gene expression are associated with cardio-metabolic traits
}

\author{
Silvana C. E. Maas 1,2, Michelle M. J. Mens' ${ }^{1}$, Brigitte Kühnel'3,4, Joyce B. J. van Meurs ${ }^{5}$, André G. Uitterlinden ${ }^{1,5}$, \\ Annette Peters ${ }^{3,4,6,7}$, Holger Prokisch ${ }^{8}$, Christian Herder ${ }^{9,10,11}$, Harald Grallert ${ }^{4}$, Sonja Kunze ${ }^{3,4}$, \\ Melanie Waldenberger ${ }^{3,4,6}$, Maryam Kavousi ${ }^{1}$, Manfred Kayser ${ }^{2}$ and Mohsen Ghanbari ${ }^{* *}$ (I)
}

\begin{abstract}
Background: Tobacco smoking is a well-known modifiable risk factor for many chronic diseases, including cardiovascular disease (CVD). One of the proposed underlying mechanism linking smoking to disease is via epigenetic modifications, which could affect the expression of disease-associated genes. Here, we conducted a three-way association study to identify the relationship between smoking-related changes in DNA methylation and gene expression and their associations with cardio-metabolic traits.

Results: We selected $2549 \mathrm{CpG}$ sites and 443 gene expression probes associated with current versus never smokers, from the largest epigenome-wide association study and transcriptome-wide association study to date. We examined three-way associations, including CpG versus gene expression, cardio-metabolic trait versus CpG, and cardio-metabolic trait versus gene expression, in the Rotterdam study. Subsequently, we replicated our findings in The Cooperative Health Research in the Region of Augsburg (KORA) study. After correction for multiple testing, we identified both cis- and trans-expression quantitative trait methylation (eQTM) associations in blood. Specifically, we found 1224 smoking-related CpGs associated with at least one of the 443 gene expression probes, and 200 smoking-related gene expression probes to be associated with at least one of the 2549 CpGs. Out of these, 109 CpGs and 27 genes were associated with at least one cardio-metabolic trait in the Rotterdam Study. We were able to replicate the associations with cardio-metabolic traits of $26 \mathrm{CpGs}$ and 19 genes in the KORA study. Furthermore, we identified a three-way association of triglycerides with two CpGs and two genes (GZMA; CLDND1), and BMI with six CpGs and two genes (PID1; LRRN3). Finally, our results revealed the mediation effect of cg03636183 (F2RL3), cg06096336 (PSMD1), cg13708645 (KDM2B), and cg17287155 (AHRR) within the association between smoking and LRRN3 expression.
\end{abstract}

Conclusions: Our study indicates that smoking-related changes in DNA methylation and gene expression are associated with cardio-metabolic risk factors. These findings may provide additional insights into the molecular mechanisms linking smoking to the development of CVD.

Keywords: Cardio-metabolic traits, Epigenetics, DNA methylation, Gene expression, Smoking

*Correspondence: m.ghanbari@erasmusmc.nl

${ }^{1}$ Department of Epidemiology, Erasmus MC University Medical Center Rotterdam, 3015 GB Rotterdam, The Netherlands

Full list of author information is available at the end of the article

\section{Background}

Tobacco smoking is a major modifiable risk factor for premature death and non-communicable diseases worldwide [1]. With almost 18 million deaths in 2017, cardiovascular diseases (CVD) account for the largest original author(s) and the source, provide a link to the Creative Commons licence, and indicate if changes were made. The images or other third party material in this article are included in the article's Creative Commons licence, unless indicated otherwise in a credit line to the material. If material is not included in the article's Creative Commons licence and your intended use is not permitted by statutory regulation or exceeds the permitted use, you will need to obtain permission directly from the copyright holder. To view a copy of this licence, visit http://creativecommons.org/licenses/by/4.0/. The Creative Commons Public Domain Dedication waiver (http://creativeco mmons.org/publicdomain/zero/1.0/) applies to the data made available in this article, unless otherwise stated in a credit line to the data. 
number of deaths of non-communicable diseases [2]. Smoking is also associated with cardio-metabolic traits, such as dyslipidemia, hypertension, insulin resistance, and obesity, which are major risk factors leading to CVD [3, 4]. Furthermore, persistent smoking has an excessive impact on DNA methylation [5-7] and gene expression [8-10], which their alterations are also linked to cardio-metabolic traits and risk of CVD [11-16].

Extensive studies have shown the independent association of smoking with DNA methylation, gene expression levels, and disease risk. In this context, smoking is associated with alteration in DNA methylation levels of several genes related to type 2 diabetes [17] and coronary artery disease [18]. Additionally, smokingrelated CpGs have a strong association with all-cause and cardiovascular mortality [19]. Nevertheless, much less research has investigated smoking-related changes in DNA methylation and gene expression concurrently and in relation to health outcomes. A recent study identified a link between smoking-related DNA methylation and gene expression changes with metabolic health [20]. Their results indicate possible molecular pathways in which smoking affects disease development.

In this study, we hypothesized that smoking-related modifications in DNA methylation and gene expression are associated with each other and, additionally, with cardio-metabolic traits. Hence, we first determined three-way associations, including CpGs versus gene expression, cardio-metabolic traits versus CpGs, cardio-metabolic traits versus gene expression. To this end, we selected CpGs and gene expression probes associated with current versus never smokers using the largest published epigenome-wide association study (EWAS) [6] and transcriptome-wide association study (TWAS) [8] to date. Next, we used data from the Rotterdam Study to test the expression quantitative trait methylation (eQTM) association between the selected $\mathrm{CpGs}$ and gene expression probes. Subsequently, we tested the association for these CpGs and genes with different cardio-metabolic traits, including lipids, glycemic indices, blood pressure, and obesity-related traits. Moreover, we performed mediation analysis to test the mediating effect of; (1) DNA methylation in the association between smoking and cardio-metabolic traits, (2) gene expression in the association between smoking and cardio-metabolic traits, and (3) DNA methylation in the association between smoking and expression levels of smoking-related genes. To test the validity of our findings, we further replicated our results in an independent cohort, The Cooperative Health Research in the Region of Augsburg (KORA) study.

\section{Results}

An overview of our study design is illustrated in Fig. 1. The discovery dataset consisted of 1412 participants with DNA methylation data from the two sub-cohorts of the Rotterdam study; RS-II and RS-III. Of these, 716 participants from RS-III had also gene expression data [21]. The replication dataset comprises 1727 participants with DNA methylation data, of whom 687 also had gene expression data, from the KORA study (F4) [22]. Both the discovery and replication cohorts consisted of both males and females (53.3\%) and current, former and never smokers. In the current study, the former and never smokers are combined in the non-smoker category (83.6\%). General characteristics of the study population are listed in Table 1.

\section{Correlation between smoking-related changes in DNA methylation and gene expression}

We selected $2623 \mathrm{CpGs}$ previously reported as being significantly $\left(P<1 \times 10^{-7}\right)$ differentially methylated between smokers and never smokers [6]. Of these, 2549 CpGs passed the quality control in the Rotterdam Study. Furthermore, we selected 502 gene expression probes that were differently expressed between smokers and never smokers $(F D R<0.05)$ and replicated in an independent dataset as part of the same study [8]. Of these, 443 gene expression probes passed quality control in the Rotterdam Study. Then, we investigated the eQTM associations to test the possible impact of smoking-related DNA methylation changes on the smoking-related genes, or vice versa. To this end, we computed the residuals for both the CpGs and gene expression probes. Then, we tested the association between all the smokingrelated CpGs with all the smoking-related gene expression probes. Here, we investigated cis-eQTMs in which the CpG regulates transcription of a neighboring gene $(\leq 250 \mathrm{~Kb}$ from each side of the transcription start site). Also, we studied the trans-eQTM association in which a CpG regulates distant genes located $>250 \mathrm{~Kb}$ of the transcription start site [23]. Notably, out of the 2549 smoking-related CpGs, 1224 were associated with at least one of the gene expression probes at the significance threshold of $P<4.4 \times 10^{-8}(0.05 / 443 \times 2549)$. Of the 443 tested gene expression probes, 200 probes were significantly associated with at least one of the 2549 CpGs, after correcting for multiple testing (Additional file 1: Table S1). The $\mathrm{R}$ code to generate the residuals for the CpGs and gene expression probes, and for the eQTM analysis are included in Additional file 2.

To examine the possible enrichment due to the smoking effect, we further tested if the number of significant eQTM associations is higher while using smoking-related 


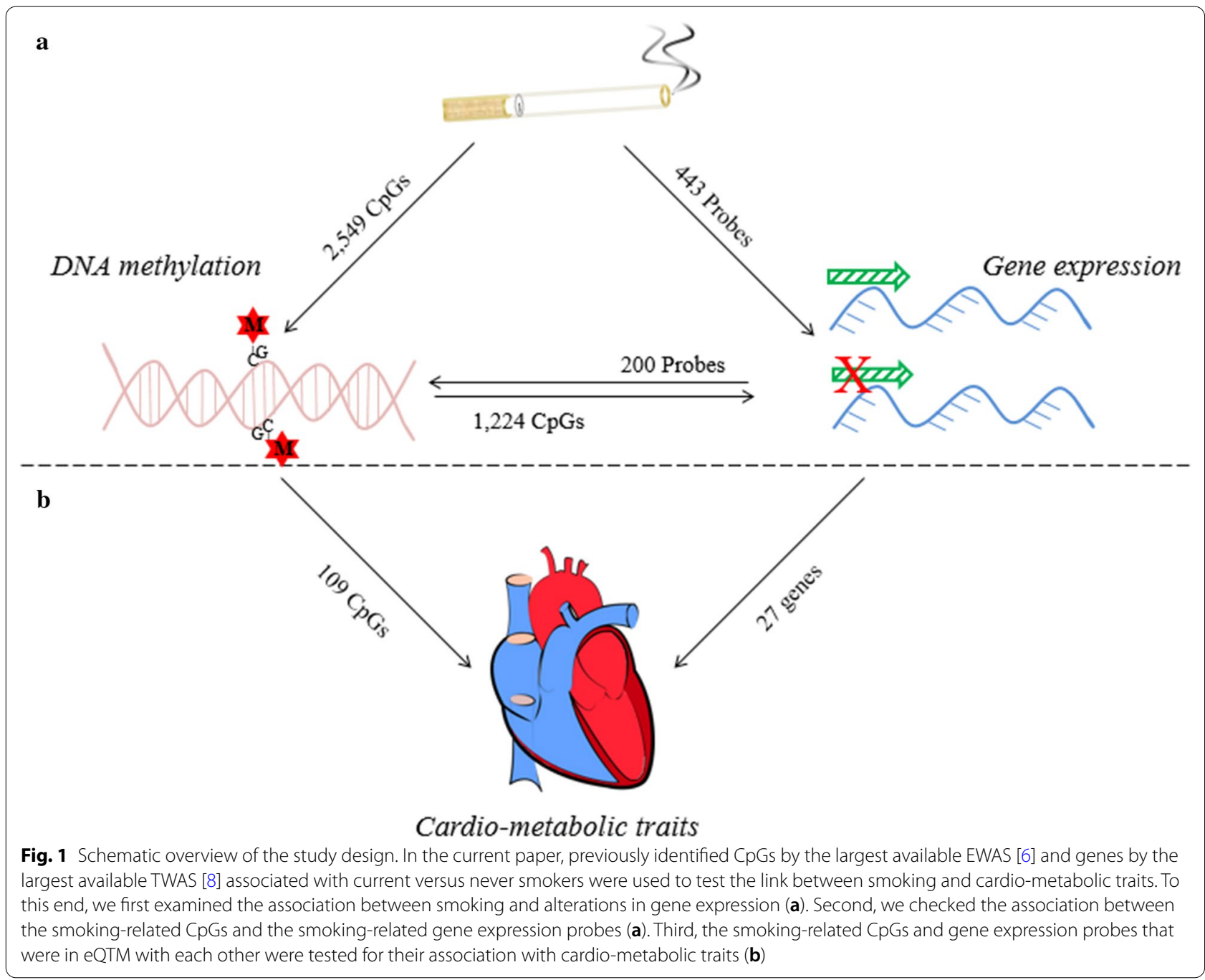

CpGs and genes, compared to the number of eQTM associations while using randomly selected $\mathrm{CpGs}$ and genes. When testing the association between the 2549 smoking-related CpGs with 443 randomly selected gene expression probes, we found that only $325 \mathrm{CpGs}$ are associated with at least one of these gene expression probes and 186 gene expression probes with at least one smoking-related CpG. Using the chi-square test of independence to compare the use of smoking-related gene expression probes versus randomly selected gene expression probes, we obtained for the CpGs (1224 vs 325 , respectively) $P<1.0 \times 10^{-5}$ and for the genes expression probes (200 vs 186 , respectively) a $P$ value of 0.38 . Similarly, when testing the association between 2549 randomly selected CpGs with the 443 smoking-related gene expression probes, we found only $465 \mathrm{CpGs}$ associated with at least one smoking-related gene expression probe, and 19 gene expression probes with at least one smoking-related $\mathrm{CpG}$. Using the chi-square test of independence, comparing the use of smoking-related CpGs versus randomly selected CpGs, we found a significant difference $\left(P<1.0 \times 10^{-5}\right)$ for both the CpGs $(1224$ vs 465 , respectively) and the gene expression probes (200 vs 19 , respectively). These results indicate enrichment of smoking-related genes in smoking-related DNA methylation sites and vice versa.

The replication in the KORA study confirmed the association of 134 smoking-related CpGs with at least one gene expression probe and 50 smoking-related gene expression probes with at least one smoking-related CpG, after correcting for multiple testing, at the significance threshold of $P<2.04 \times 10^{-7}(0.05 / 200 \times 1224)$.

\section{Association of smoking-related changes in DNA methylation and gene expression with cardio-metabolic traits}

We tested the association of the 1224 CpGs and the 200 gene expression probes with cardio-metabolic traits, 
Table 1 Population characteristics

\begin{tabular}{|c|c|c|c|c|}
\hline & \multicolumn{2}{|l|}{ Discovery dataset } & \multicolumn{2}{|l|}{ Replication dataset } \\
\hline & $\begin{array}{l}\text { Gene expression data } \\
\text { set }\end{array}$ & $\begin{array}{l}\text { DNA methylation data } \\
\text { set }\end{array}$ & $\begin{array}{l}\text { Gene expression data } \\
\text { set }\end{array}$ & $\begin{array}{l}\text { DNA } \\
\text { methylation } \\
\text { data set }\end{array}$ \\
\hline N & 716 & 1412 & 687 & 1727 \\
\hline Female & $389(54.3 \%)$ & $791(56.0 \%)$ & $339(49.3 \%)$ & $882(51.0 \%)$ \\
\hline Age (years) & $59.8( \pm 8.1)$ & $63.6( \pm 8.1)$ & $69.1( \pm 4.4)$ & $61.0( \pm 8.8)$ \\
\hline BMI $\left(\mathrm{kg} / \mathrm{m}^{2}\right)$ & $27.6( \pm 4.6)$ & $27.7( \pm 4.4)$ & $28.9( \pm 4.5)$ & $28.1( \pm 4.8)$ \\
\hline WHR & $0.9( \pm 0.1)$ & $0.9( \pm 0.1)$ & $0.9( \pm 0.1)$ & $0.9( \pm 0.1)$ \\
\hline Current smokers & $193(27.0 \%)$ & $266(18.0 \%)$ & $53(7.7 \%)$ & $250(14.5 \%)$ \\
\hline Triglycerides (mmol/L) & $1.5( \pm 0.9)$ & $1.5( \pm 0.8)$ & $1.5( \pm 0.9)$ & $1.5( \pm 1.1)$ \\
\hline HDL-cholesterol (mmol/L) & $1.4( \pm 0.4)$ & $1.5( \pm 0.4)$ & $1.4( \pm 0.4)$ & $1.5( \pm 0.4)$ \\
\hline LDL-cholesterol (mmol/L) & $3.9( \pm 1.0)$ & $3.8( \pm 1.0)$ & $3.7( \pm 0.9)$ & $3.6( \pm 0.9)$ \\
\hline Total cholesterol (mmol/L) & $5.6( \pm 1.1)$ & $5.5( \pm 1.0)$ & $5.8( \pm 1.0)$ & $5.7( \pm 1.0)$ \\
\hline Lipid lowering medication (yes) & $190(26.5 \%)$ & $404(28.6 \%)$ & $172(25.0 \%)$ & $283(16.4 \%)$ \\
\hline Systolic blood pressure $(\mathrm{mm} \mathrm{Hg})$ & $134.2( \pm 19.8)$ & $139.5( \pm 21.5)$ & $128.7( \pm 19.4)$ & $124.8( \pm 18.7)$ \\
\hline Diastolic blood pressure $(\mathrm{mm} \mathrm{Hg})$ & $82.8( \pm 11.4)$ & $83.6( \pm 11.5)$ & $74.7( \pm 10.0)$ & $76.1( \pm 10.0)$ \\
\hline Anti-hypertensive medication (yes) & $215(30.0 \%)$ & $517(36.6 \%)$ & $383(55.7 \%)$ & $650(37.6 \%)$ \\
\hline Glucose (mmol/L) & $5.6( \pm 1.0)$ & $5.6( \pm 1.1)$ & NA & NA \\
\hline Insulin (pmol/L) & $96.0( \pm 63.0)$ & $89.3( \pm 56.6)$ & $88.2( \pm 122.0)$ & $81.3( \pm 91.0)$ \\
\hline Anti-diabetic medication (yes) & $39(5.4 \%)$ & $95(6.7 \%)$ & $76(11.1 \%)$ & $134(7.8 \%)$ \\
\hline
\end{tabular}

Values are presented as mean $\pm(\mathrm{SD})$ or $N(\%)$

$B M I$ body mass index, WHR waist to hip ratio, HDL high-density lipoproteins, $L D L$ low-density lipoprotein

The participants included in the gene expression data are a subset of the total DNA methylation dataset

$N A$ not applicable; the associations with glucose levels in model 2 from the discovery did not pass the significance threshold

including high-density lipoprotein (HDL), low-density lipoprotein (LDL), triglycerides (TG) and serum cholesterol, fasting glucose and insulin levels, systolic blood pressure (SBP) and diastolic blood pressure (DBP), waist to hip ratio (WHR) and body mass index (BMI) in the Rotterdam Study. After adjusting for age, sex, blood cell count, and technical covariates (model 1), we found significant associations between 202 out of the 1224 smoking-related $\mathrm{CpGs}$ and any cardio-metabolic trait at $P<4.08 \times 10^{-5} \quad(0.05 / 1224) \quad(n=1412$ participants $)$ (Additional file 3: Table S2). Among these, we observed associations with HDL (126 CpGs), TG (84 CpGs), glucose (2 CpGs), insulin (10 CpGs), DBP (1 CpG), WHR (21 CpGs), and BMI (16 CpGs). After further adjustment for BMI and relevant medication in the model 2, associations with 109 CpGs remained significant, including HDL (58 CpGs), TG (35 CpGs), DBP (1 CpG), WHR (6 CpG), and BMI (16 CpG same as model 1) (Additional file 3: Table S3). The $\mathrm{R}$ code to test the association between cardio-metabolic traits and the CpGs are included in Additional file 4. We pursued replication in the KORA study for the CpGs reaching significance in the model 2 and found that $26 \mathrm{CpGs}$ surpassed the nominal significance $(P<0.05, n=1727$ participants $)$, including $8 \mathrm{CpGs}$ for $\mathrm{HDL}, 8 \mathrm{CpGs}$ for TG, 4 CpGs for WHR, and 7 CpGs for BMI (Table 2, Additional file 3: Table S3). The direction of associations with cardiometabolic traits was consistent in all 26 replicated CpGs. Based on the stringent Bonferroni-adjusted $P$ value threshold, the replication signals were significant at $2 \mathrm{CpGs}$ for TG $\left(P<0.05 / 35=1.43 \times 10^{-3}\right)$, $3 \mathrm{CpGs}$ for WHR $\left(P<0.05 / 6=8.33 \times 10^{-3}\right)$, and 4 CpGs with BMI $\left(P<0.05 / 16=3.13 \times 10^{-3}\right)$ (Table 2 and Fig. 2$)$.

Furthermore, out of the 200 smoking-related gene expression probes 39 (35 genes) were significantly associated with at least one cardio-metabolic trait at $P<2.5 \times 10^{-4}(0.05 / 200)$ in the Rotterdam Study $(n=716$ participants) (Additional file 2: Table S4). In the Illumina HumanHT-12 Expression BeadChip array, some of the annotated genes have more than one probe. Therefore, we adjusted the analysis for the number of probes we tested and provided both the probe ID and annotated gene in the tables. Of the 39 probes, we found associations with HDL (15 genes), LDL (1 gene), TG (18 genes), cholesterol (1 gene), glucose (3 genes), insulin (13 genes), WHR (6 genes), and BMI (14 genes). After further adjustments in model 2 , the associations of 29 probes ( 27 genes) remained significant, including HDL (5 genes), LDL (1 
Table 2 CpG sites associated with cardio-metabolic traits in DNA methylation analysis

\begin{tabular}{|c|c|c|c|c|c|c|c|c|c|}
\hline \multirow[t]{2}{*}{ CpG } & \multirow[t]{2}{*}{ Chr:position ${ }^{a}$} & \multirow[t]{2}{*}{ Gene ID ${ }^{b}$} & \multirow[t]{2}{*}{ Trait } & \multicolumn{2}{|l|}{ Model 1} & \multicolumn{2}{|l|}{ Model 2} & \multicolumn{2}{|l|}{ Replication } \\
\hline & & & & Effect & $P$ value & Effect & $P$ value & Effect & $P$ value \\
\hline cg04716530 & 16:30485684 & ITGAL & $\mathrm{HDL}$ & 0.01700 & $2.02 \mathrm{E}-07$ & 0.01550 & $6.34 \mathrm{E}-06$ & 0.00014 & $9.82 \mathrm{E}-04$ \\
\hline cg07826859 & 7:45020086 & MYO1G & $\mathrm{HDL}$ & 0.01440 & $6.79 E-06$ & 0.01390 & $3.61 \mathrm{E}-05$ & 0.00018 & $1.61 \mathrm{E}-03$ \\
\hline cg26724967 & 16:3115223 & IL32 & $\mathrm{HDL}$ & 0.01290 & $2.89 E-06$ & 0.01220 & $2.34 \mathrm{E}-05$ & 0.00015 & $1.63 E-03$ \\
\hline cg16391678 & 16:30485597 & ITGAL & $\mathrm{HDL}$ & 0.01520 & $1.03 \mathrm{E}-06$ & 0.01400 & $1.60 \mathrm{E}-05$ & 0.00013 & $5.14 \mathrm{E}-03$ \\
\hline cg16519923 & $16: 30485810$ & ITGAL & $\mathrm{HDL}$ & 0.01980 & $8.23 \mathrm{E}-08$ & 0.01790 & $3.44 \mathrm{E}-06$ & 0.00012 & $9.75 E-03$ \\
\hline cg10310310 & 7:157367150 & PTPRN2;MIR153-2 & $\mathrm{HDL}$ & 0.01130 & $4.49 \mathrm{E}-06$ & 0.01060 & 4.05E-05 & 0.00011 & $1.96 \mathrm{E}-02$ \\
\hline cg24323726 & 3:111314186 & ZBED2;CD96 & $\mathrm{HDL}$ & 0.01300 & $4.84 \mathrm{E}-07$ & 0.01230 & $5.32 \mathrm{E}-06$ & 0.00009 & $3.41 \mathrm{E}-02$ \\
\hline cg07929642 & 16:89390685 & ANKRD11 & $\mathrm{HDL}$ & 0.01650 & $1.87 \mathrm{E}-07$ & 0.01550 & $3.13 \mathrm{E}-06$ & 0.00009 & $4.25 \mathrm{E}-02$ \\
\hline cg21566642 & 2:233284661 & - & TG & -0.01990 & $3.89 \mathrm{E}-05$ & -0.02150 & $1.91 \mathrm{E}-05$ & -0.01967 & $1.14 \mathrm{E}-05$ \\
\hline cg04716530 & $16: 30485684$ & ITGAL & $\mathrm{TG}$ & -0.01370 & $1.23 \mathrm{E}-06$ & -0.01220 & $3.58 \mathrm{E}-05$ & -0.00380 & $5.34 \mathrm{E}-04$ \\
\hline cg27409015 & 2:158114424 & GALNT5 & TG & 0.01660 & $8.39 \mathrm{E}-07$ & 0.01490 & $2.16 \mathrm{E}-05$ & 0.00683 & $1.50 E-03$ \\
\hline cg06635952 & $2: 70025869$ & ANXA4 & TG & 0.01300 & $9.06 \mathrm{E}-07$ & 0.01280 & $3.36 \mathrm{E}-06$ & 0.00502 & $5.95 \mathrm{E}-03$ \\
\hline cg11095027 & 11:1297066 & TOLLIP & TG & 0.00996 & $2.72 \mathrm{E}-05$ & 0.01040 & $2.64 \mathrm{E}-05$ & 0.00375 & $7.82 \mathrm{E}-03$ \\
\hline cg26219092 & 8:134388022 & - & TG & 0.01050 & $2.37 \mathrm{E}-06$ & 0.00991 & $2.05 E-05$ & 0.00285 & $1.73 E-02$ \\
\hline cg10919522 & 14:74227441 & C14orf43 & TG & -0.01410 & 7.90E-09 & -0.01260 & 7.97E-07 & -0.00491 & $1.91 \mathrm{E}-02$ \\
\hline cg22635096 & 21:46550644 & $A D A R B 1$ & TG & 0.01370 & $6.61 \mathrm{E}-08$ & 0.01300 & $8.65 \mathrm{E}-07$ & 0.00392 & $3.55 \mathrm{E}-02$ \\
\hline cg00310412 & $15: 74724918$ & SEMATA & WHR & -0.05000 & $3.96 \mathrm{E}-05$ & -0.07150 & $1.95 \mathrm{E}-07$ & -0.06952 & 4.54E-05 \\
\hline cg04424621 & 6:27101941 & HIST1H2BJ & WHR & -0.06490 & $1.06 \mathrm{E}-05$ & -0.07360 & $1.03 \mathrm{E}-05$ & -0.07191 & $5.73 \mathrm{E}-05$ \\
\hline cg04583842 & $16: 88103117$ & BANP & WHR & 0.12600 & $5.29 \mathrm{E}-08$ & 0.12500 & $1.56 \mathrm{E}-06$ & 0.06802 & $3.71 \mathrm{E}-03$ \\
\hline cg13755776 & $11: 3602845$ & - & WHR & -0.08530 & $1.03 \mathrm{E}-06$ & -0.08200 & $3.33 \mathrm{E}-05$ & -0.04521 & $3.71 \mathrm{E}-02$ \\
\hline cg17287155 & 5:393347 & $A H R R$ & $\mathrm{BMI}$ & 0.00117 & $8.69 \mathrm{E}-06$ & NA & NA & 0.00053 & $3.11 \mathrm{E}-06$ \\
\hline cg26361535 & 8:144576604 & $\mathrm{ZC} 3 \mathrm{H}_{3}$ & BMI & 0.00155 & $1.85 \mathrm{E}-07$ & NA & NA & 0.00102 & $2.38 \mathrm{E}-05$ \\
\hline $\mathrm{cg} 06096336$ & 2:231989800 & PSMD1;HTR2B & BMI & 0.00168 & $9.51 \mathrm{E}-07$ & NA & NA & 0.00111 & $1.66 \mathrm{E}-04$ \\
\hline cg13708645 & 12:121974305 & $K D M 2 B$ & BMI & 0.00152 & $6.72 \mathrm{E}-07$ & NA & NA & 0.00089 & $1.01 \mathrm{E}-03$ \\
\hline cg25649826 & 17:20938740 & USP22 & BMI & 0.00086 & $1.63 \mathrm{E}-05$ & NA & NA & 0.00041 & $3.15 E-03$ \\
\hline cg24539517 & 10:121161258 & GRK5 & BMI & 0.00149 & $2.95 \mathrm{E}-05$ & NA & NA & 0.00078 & 4.33E-03 \\
\hline cg03636183 & 19:17000585 & $F 2 R L 3$ & BMl & 0.00160 & $3.04 \mathrm{E}-05$ & NA & NA & 0.00063 & $3.40 E-02$ \\
\hline
\end{tabular}

The table shows $26 \mathrm{CpGs}$ that are associated to at least one cardio-metabolic trait and in eQTM with at least one smoking-related gene-expression probe Only CpGs significantly associated in both models and nominally significant $(P<0.05)$ in the replication are presented in this table

$H D L$ high-density lipoprotein, TG triglycerides, WHR waist to hip ratio, BMI body mass index, NA not applicable (because of adjusting for BMI)

Model 1: Adjusted for age, sex, cell count, and technical covariates. Model 2: Model $1+\mathrm{BMI}$ and relevant medication

We did not correct for additional covariates when testing the association for BMI

$P$ value threshold for discovery $P<4.08 \times 10^{-5}(0.05 / 1224)$

$P$ value threshold for replication: $\mathrm{HDL}, P<8.62 \times 10^{-4}(0.05 / 58) ; \mathrm{TG}, P<1.43 \times 10^{-3}(0.05 / 35) ; \mathrm{WHR}, P<8.33 \times 10^{-3}(0.05 / 6) ; \mathrm{BMI}, P<3.13 \times 10^{-3}(0.05 / 16)$

CpGs that are presented underlined passed the replication $P$ value threshold in 1727 participants of the KORA study

a Genome coordinates provided by Illumina (GRCh37/hg19)

b According to the Illumina Infinium HumanMethylation450K annotation file

gene), TG (14 genes), cholesterol (1 gene), and insulin (2 genes), for the association with BMI nothing changed (14 genes) (Additional file 3: Table S5). The R code to test the association between cardio-metabolic traits and the gene expression probes is included in Additional file 5. Replication in the KORA study for the gene expression probes that reached significance in model 2 showed 21 probes $(19$ genes) that passed the nominal significance $(P<0.05$, $n=687$ participants). These include 2 genes for HDL, 13 genes for TG, 1 gene for insulin, and 10 genes for BMI
(Table 3, Additional file 3: Table S5). The direction of the association between gene expression and cardio-metabolic traits was consistent for all these genes. Based on the stringent Bonferroni-adjusted P-value in which we adjusted for the number of probes, the replication signal was significant at 2 genes for HDL $(P<0.05 / 5=0.01)$, 11 genes for TG $\left(P<0.05 / 15=3.33 \times 10^{-3}\right), 1$ gene for insulin $(P<0.05 / 2=0.025)$, and 4 genes for BMI $\left(P<0.05 / 16=3.13 \times 10^{-3}\right)$. Several of these genes were associated in model 2 with more than one 


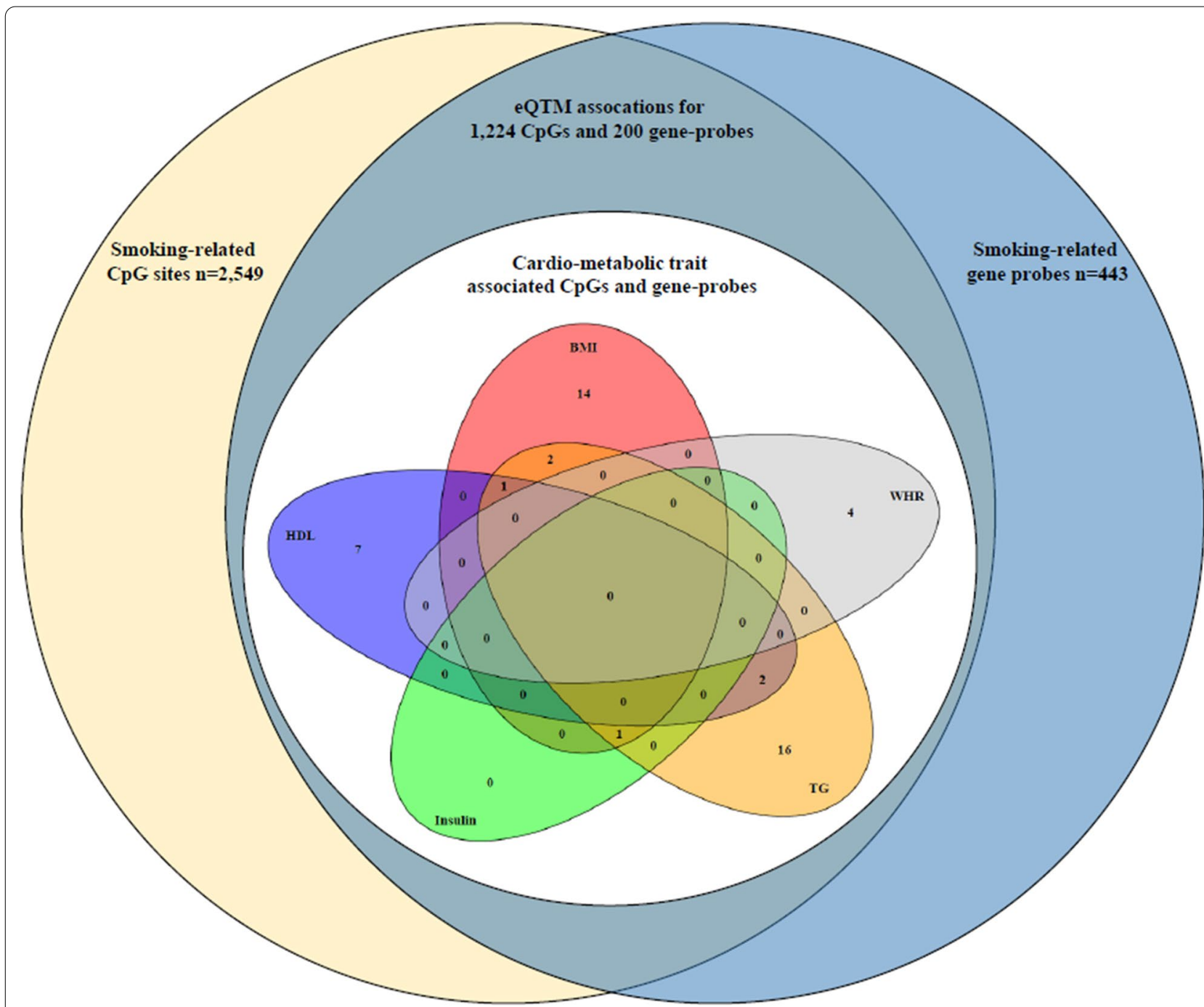

Fig. 2 The overlap of smoking-related CpGs and genes in association with cardio-metabolic traits. In the current study, 2549 smoking-related CpGs and 443 smoking-related gene expression probes were included. Of these, 1224 CpGs and 200 gene expression probes showed eQTM association. We found the association for $26 \mathrm{CpGs}$ and 19 genes (21 expression probes) with at least one cardio-metabolic traits, which surpassing the nominal significance $(P<0.05)$ in the KORA replication study

cardio-metabolic trait and were replicated at least at the nominal significance $(P<0.05)$. For example, $K L R B 1$ (ILMN_2079655), ITM2C (ILMN_2366041), and CD3D (ILMN_2261416) were associated with both TG and BMI, and OCIAD2 (ILMN_1700306) was associated with both HDL and TG, and EFHD2 (ILMN_1761463) was associated with HDL, TG, and BMI (Table 3 and Fig. 2).

Next, we explored whether there is an overlap in the results obtained with DNA methylation and gene expression data, which possibly explain the link between smoking and cardio-metabolic traits. Table 4 shows the overlap of the replicated association of cardio-metabolic traits with gene expression, which were both also associated with the smoking-related CpGs, indicating a three-way association (Fig. 1). Additional file 3: Table S6 displays the three-way association as obtained in our discovery dataset. For example, we found in the Rotterdam Study overlapping association of serum HDL levels with four CpGs (cg01305745, cg06177555, cg07990556, and cg16448702) and expression levels of three genes (EFHD2, PRF1, and OSBPL5). Likewise, we found the association of TG levels with 18 CpGs and six genes (ICOS, GZMA, C12orf57, $C D 3 D, C L D N D 1$, and $E F H D 2)$. Finally, we found BMI to be associated with $16 \mathrm{CpGs}$ and five genes (LRRN3, EFHD2, PID1, STOM, and CD3D) (Additional file 3: Table S6). Of these, we were able to replicate the threeway association of TG with DNA methylation levels of cg04716530 and expression levels of GZMA, and DNA 
Table 3 Gene expression probes associated with cardio-metabolic traits

\begin{tabular}{|c|c|c|c|c|c|c|c|c|c|}
\hline \multirow[t]{2}{*}{ Probe ID } & \multirow[t]{2}{*}{ Gene ID ${ }^{a}$} & \multirow[t]{2}{*}{ Chr. ${ }^{a}$} & \multirow[t]{2}{*}{ Trait } & \multicolumn{2}{|l|}{ Model 1} & \multicolumn{2}{|l|}{ Model 2} & \multicolumn{2}{|c|}{ Replication } \\
\hline & & & & Effect & $P$ value & Effect & $P$ value & Effect & $P$ value \\
\hline$\underline{\text { ILMN_1700306 }}$ & OCIAD2 & 4 & $\mathrm{HDL}$ & -0.4114 & $8.39 E-07$ & -0.3573 & $5.15 E-05$ & -0.0040 & $9.20 \mathrm{E}-05$ \\
\hline$\underline{\text { ILMN_1761463 }}$ & EFHD2 & 1 & $\mathrm{HDL}$ & 0.4668 & $1.60 \mathrm{E}-07$ & 0.3576 & 0.00013 & 0.0022 & $1.38 \mathrm{E}-03$ \\
\hline ILMN_2261416 & $C D 3 D$ & 11 & $\mathrm{TG}$ & 0.9089 & $2.22 \mathrm{E}-15$ & 0.8328 & $3.84 \mathrm{E}-12$ & 0.3233 & $2.58 \mathrm{E}-15$ \\
\hline ILMN_2079655 & $K L R B 1$ & 12 & $\mathrm{TG}$ & 1.1666 & $6.48 \mathrm{E}-14$ & 1.0518 & $1.01 \mathrm{E}-10$ & 0.3946 & $4.09 \mathrm{E}-15$ \\
\hline$\underline{\text { ILMN_1779324 }}$ & GZMA & 5 & $\mathrm{TG}$ & 1.0562 & $1.99 \mathrm{E}-09$ & 1.0033 & $6.01 \mathrm{E}-08$ & 0.2734 & $2.06 \mathrm{E}-13$ \\
\hline$\underline{\text { ILMN_1761463 }}$ & EFHD2 & 1 & TG & -0.4238 & $2.59 \mathrm{E}-09$ & -0.3434 & $3.54 \mathrm{E}-06$ & -0.1298 & $9.99 \mathrm{E}-13$ \\
\hline$\underline{\text { ILMN_1700306 }}$ & OCIAD2 & 4 & TG & 0.3413 & $3.32 \mathrm{E}-07$ & 0.2998 & $1.93 \mathrm{E}-05$ & 0.1691 & $7.64 \mathrm{E}-10$ \\
\hline ILMN_1808939 & RPS6 & 9 & $\mathrm{TG}$ & 0.6145 & $5.58 \mathrm{E}-11$ & 0.5687 & $7.54 \mathrm{E}-09$ & 0.3001 & 1.17E-09 \\
\hline ILMN_1812191 & C12orf57 & 12 & TG & 0.4392 & $1.37 \mathrm{E}-05$ & 0.3897 & 0.00023 & 0.1772 & $1.07 \mathrm{E}-07$ \\
\hline$\underline{\text { ILMN_1776181 }}$ & BIRC3 & 11 & $\mathrm{TG}$ & 0.6940 & $2.86 \mathrm{E}-10$ & 0.6176 & $8.34 \mathrm{E}-08$ & 0.1473 & $4.89 \mathrm{E}-07$ \\
\hline$\underline{\text { LLMN_1813836 }}$ & DARS & 2 & $\mathrm{TG}$ & 0.2657 & $9.37 \mathrm{E}-07$ & 0.2878 & 4.67E-07 & 0.0894 & $3.18 \mathrm{E}-06$ \\
\hline$\underline{\text { ILMN_1669927 }}$ & ICOS & 2 & $\mathrm{TG}$ & 0.2859 & $6.88 \mathrm{E}-06$ & 0.2692 & 5.75E-05 & 0.0925 & $2.95 \mathrm{E}-04$ \\
\hline$\underline{\text { LLMN_2198878 }}$ & INPP4B & 4 & $\mathrm{TG}$ & 0.2950 & $2.99 \mathrm{E}-07$ & 0.2853 & $2.53 \mathrm{E}-06$ & 0.0668 & $5.93 \mathrm{E}-04$ \\
\hline ILMN_2366041 & ITM2C & 2 & TG & -0.5648 & $6.81 \mathrm{E}-09$ & -0.4159 & $3.35 \mathrm{E}-05$ & -0.0818 & $6.33 \mathrm{E}-03$ \\
\hline ILMN_1680453 & ITM2C & 2 & $\mathrm{TG}$ & -0.5880 & $5.50 \mathrm{E}-08$ & -0.4295 & 0.000124 & -0.0818 & $7.05 \mathrm{E}-03$ \\
\hline ILMN_2352563 & CLDND1 & 3 & $\mathrm{TG}$ & 0.3877 & $4.61 E-05$ & 0.4003 & $6.52 \mathrm{E}-05$ & 0.0656 & $3.53 \mathrm{E}-02$ \\
\hline ILMN_2079655 & $K L R B 1$ & 12 & Insulin & 0.7694 & 7.01E-09 & 0.6393 & $5.21 \mathrm{E}-05$ & 0.2120 & $5.59 \mathrm{E}-05$ \\
\hline$\underline{\text { ILMN_ } 1766657}$ & STOM & 9 & BMI & 0.0549 & $3.85 \mathrm{E}-07$ & NA & NA & 0.0196 & $2.56 \mathrm{E}-08$ \\
\hline ILMN_1671891 & PID1 & 2 & BMI & -0.0425 & 7.23E-09 & NA & NA & -0.0137 & $3.27 \mathrm{E}-06$ \\
\hline$\underline{\text { ILMN } 2366041}$ & ITM2C & 2 & BMI & -0.0577 & $1.86 \mathrm{E}-09$ & NA & NA & -0.0123 & $9.53 \mathrm{E}-05$ \\
\hline$\underline{\text { ILMN } 1773650}$ & LRRN3 & 7 & BMl & -0.0669 & $3.77 \mathrm{E}-05$ & NA & NA & -0.0162 & $1.70 \mathrm{E}-03$ \\
\hline ILMN_1661599 & DDIT4 & 10 & BMl & -0.0658 & $2.75 \mathrm{E}-07$ & NA & NA & -0.0096 & $4.06 \mathrm{E}-03$ \\
\hline ILMN_2048591 & LRRN3 & 7 & $\mathrm{BMl}$ & -0.0604 & $1.46 \mathrm{E}-05$ & NA & NA & -0.0086 & $6.95 \mathrm{E}-03$ \\
\hline ILMN_2377669 & CD247 & 1 & BMI & -0.0370 & $5.95 \mathrm{E}-05$ & NA & NA & -0.0058 & $8.01 \mathrm{E}-03$ \\
\hline ILMN_2109197 & $E P B 41 L 3$ & 18 & BMI & -0.0322 & 0.000112 & NA & NA & -0.0072 & $1.12 \mathrm{E}-02$ \\
\hline ILMN_2261416 & $C D 3 D$ & 11 & BMl & 0.0458 & $6.47 \mathrm{E}-05$ & NA & NA & 0.0107 & 1.37E-02 \\
\hline ILMN_2079655 & $K L R B 1$ & 12 & BMI & 0.0669 & $1.63 \mathrm{E}-05$ & NA & NA & 0.0122 & $2.29 \mathrm{E}--02$ \\
\hline ILMN_1761463 & EFHD2 & 1 & BMI & -0.0339 & $1.46 \mathrm{E}-06$ & NA & NA & -0.0038 & $4.68 \mathrm{E}-02$ \\
\hline
\end{tabular}

The table shows 21 probes annotated to 19 genes that are significantly associated with cardio-metabolic traits and in eQTM with at least one smoking-related CpG Only probes significantly associated in both models and nominally significant $(P<0.05)$ in the replication are presented in this table $H D L$ high-density lipoprotein, $T G$ triglycerides, BMI body mass index, NA not applicable (because of adjusting for BMI)

Model 1: Adjusted for age, sex, cell count, RNA quality score, and technical covariates. Model 2: Model $1+$ BMI and relevant medication We did not correct for additional covariates when testing the association for BMI

$P$ value threshold $P<2.25 \times 10^{-4}(0.05 / 200)$

$P$ value threshold for replication: $\mathrm{HDL}, P<0.01,(0.05 / 5)$; TG, $P<3.33 \times 10^{-3}(0.05 / 15)$; Insulin, $P<0.03(0.05 / 2) ; \mathrm{BMI}, P<3.13 \times 10^{-3}(0.05 / 16)$

Genes that are presented underlined passed the replication $p$ value threshold in 687 participants of the KORA study

a According to the by Illumina provided annotation file

methylation levels of $\operatorname{cg} 21566642$ and expression levels of CLDND1 in the KORA study. Furthermore, we found BMI to be associated with DNA methylation levels of 6 CpGs and expression of two genes (LRRN3 and PID1) (Table 4).

In the three-way association (Table 4), we also identified CpGs associated with expression levels of genes far approximate from their annotated gene/loci. We did a lookup for the identified CpGs for eQTM association using data from the BIOS-BBMRI database (https ://www.genenetwork.nl/biosqtlbrowser/). Here, we found cis-eQTMs between cg17287155 and expression of EXOC3 and between cg03636183 and expression of F2RL3. In the Rotterdam Study, both EXOC3 and $F 2 R L 3$ gene expression probes did not pass the QC. Hence, we could not test the influence of these genes in the identified eQTM associations in a three-way analysis. 
Table 4 The DNA methylation sites associated with gene

\begin{tabular}{|c|c|c|c|c|c|c|c|c|}
\hline \multicolumn{3}{|l|}{ Gene expression $^{a}$} & \multirow[t]{2}{*}{ Trait } & \multicolumn{3}{|c|}{ DNA methylation ${ }^{\mathbf{b}}$} & \multicolumn{2}{|l|}{ eQTMc } \\
\hline ProbelD & Effect & $P$ value & & CpG & Effect & $P$ value & Coeff & $P$ value \\
\hline ILMN_1779324 (GZMA) & 1.0033 & $6.01 \mathrm{E}-08$ & TG & $\underline{\operatorname{cg} 04716530}$ & -0.0122 & $3.58 \mathrm{E}-05$ & -11.7641 & $6.91 \mathrm{E}-12$ \\
\hline ILMN_2352563 (CLDND1) & 0.4003 & $6.52 \mathrm{E}-05$ & $\mathrm{TG}$ & cg21566642 & -0.0215 & $1.91 \mathrm{E}-05$ & -5.1957 & $3.54 \mathrm{E}-19$ \\
\hline ILMN_1671891 (PID1) & -0.0425 & 7.23E-09 & BMl & cg03636183 & 0.0016 & $3.04 \mathrm{E}-05$ & -3.9797 & $1.28 \mathrm{E}-11$ \\
\hline \multirow[t]{6}{*}{ ILMN_1773650 (LRRN3) } & -0.0669 & 3.77E-05 & BMI & cg03636183 & 0.0016 & $3.04 \mathrm{E}-05$ & -16.4622 & $3.46 \mathrm{E}-41$ \\
\hline & & & & $\mathrm{cg} 06096336$ & 0.0017 & $9.51 \mathrm{E}-07$ & -15.0031 & $2.91 \mathrm{E}-24$ \\
\hline & & & & cg13708645 & 0.0015 & $6.72 \mathrm{E}-07$ & -9.5025 & $2.31 \mathrm{E}-09$ \\
\hline & & & & cg17287155 & 0.0012 & $8.69 \mathrm{E}-06$ & -26.2306 & $3.09 E-54$ \\
\hline & & & & cg25649826 & 0.0009 & $1.63 \mathrm{E}-05$ & -14.4989 & $3.43 \mathrm{E}-08$ \\
\hline & & & & $\mathrm{cg} 26361535$ & 0.0016 & $1.85 \mathrm{E}-07$ & -12.549 & $2.30 E-11$ \\
\hline \multirow[t]{4}{*}{ ILMN_2048591 ( LRRN3) } & -0.0604 & $1.46 \mathrm{E}-05$ & BMl & cg03636183 & 0.0016 & $3.04 \mathrm{E}-05$ & -14.4435 & $2.67 E-43$ \\
\hline & & & & $\mathrm{cg} 06096336$ & 0.0017 & $9.51 \mathrm{E}-07$ & -11.5428 & $1.40 \mathrm{E}-19$ \\
\hline & & & & cg13708645 & 0.0015 & $6.72 \mathrm{E}-07$ & -8.2627 & $1.36 \mathrm{E}-09$ \\
\hline & & & & cg17287155 & 0.0012 & $8.69 E-06$ & -21.4408 & $1.19 E-48$ \\
\hline
\end{tabular}

The table shows an overview of the overlap of the hits with nominal significant $(P<0.05)$ replication in KORA in all three association analyses, including the association between (1) DNA methylation and cardio-metabolic traits, (2) gene expression and cardio-metabolic traits, and (3) the eQTM results for the gene and CpG that are associated with the same cardio-metabolic trait

$P$ value thresholds in the discovery for DNA methylation $P<4.08 \times 10^{-5}(0.05 / 1224)$, gene expression $P<2.25 \times 10^{-4}(0.05 / 200)$ and for eQTM $P<4.4 \times 10^{-8}$ $(0.05 / 443 \times 2549)$

$P$ value thresholds in the replication for TG; gene expression $P<3.33 \times 10^{-3}(0.05 / 15)$, DNA methylation $P<1.43 \times 10^{-3}(0.05 / 35)$, and BMl; gene expression

$P<3.13 \times 10^{-3}(0.05 / 16)$, DNA methylation $P<3.13 \times 10^{-3}(0.05 / 16)$, and eQTM $P<2.04 \times 10^{-7}(0.05 / 1224 \times 200)$

Results that are presented underlined passed the replication $P$ value threshold in the KORA study

$T G$ triglycerides, $B M I$ body mass index

a Expression probe cardio-metabolic trait + age, sex, cell count, RNA quality score, technical covariates, BMI and relevant medication

b CpGs cardio-metabolic trait + age, sex, cell count, technical covariates, BMI and relevant medication

c Expression probe $\sim \mathrm{CpGs}+$ age, sex

\section{Mediation analysis for smoking-related CpGs and genes associated with cardio-metabolic traits}

As shown in Fig. 3, we used mediation analysis to investigate the effect of DNA methylation and gene expression, independently, in the association between smoking and cardio-metabolic traits. Also, we tested the mediating effect of DNA methylation in the association between smoking and gene expression. In total, we conducted three different models; first, gene expression as a mediator in the observed association between smoking and cardio-metabolic traits (A1 and A2 in Fig. 3); second, DNA methylation as a mediator in the observed association

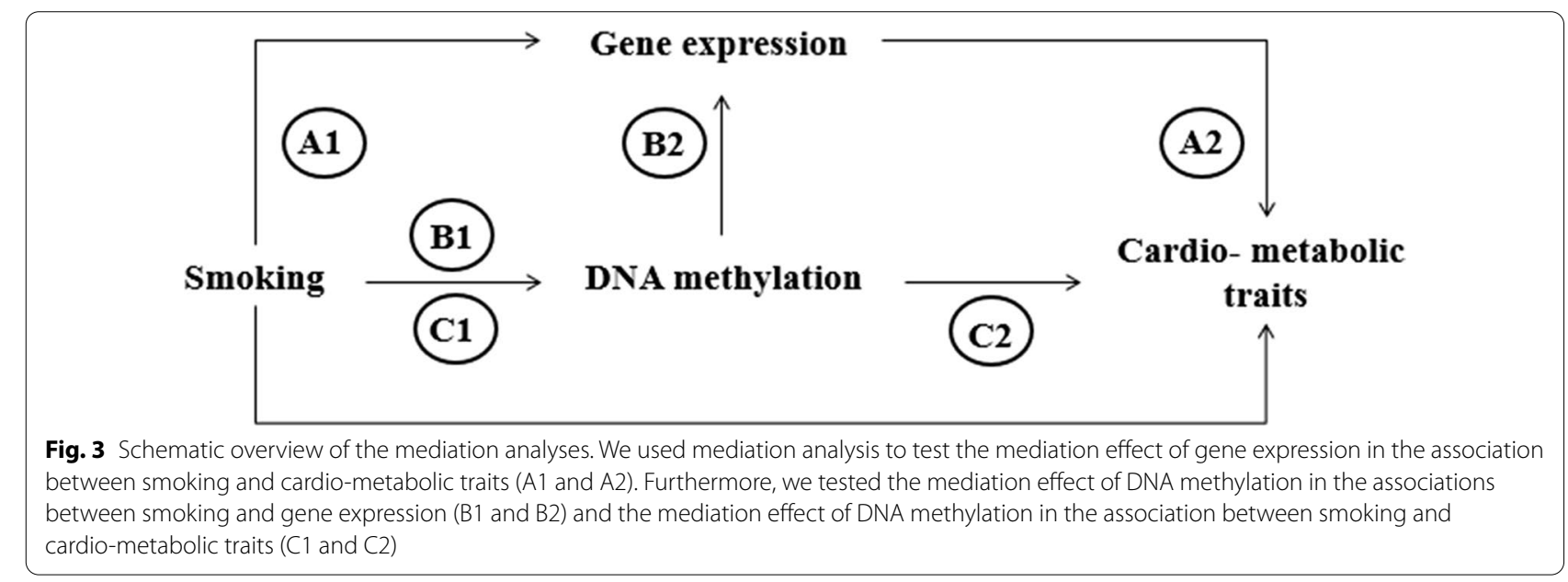


between smoking and gene expression (B1 and B2 in Fig. 3); and third, DNA methylation as the mediator in the association between smoking and cardio-metabolic traits ( $\mathrm{C} 1$ and $\mathrm{C} 2$ in Fig. 3). We conducted the average causal mediation effect (ACME), average direct effect (ADE), and the proportion mediated (Prop. med.), which are illustrated in Table 5 (and Additional file 3: Table S7). The ADE reflects the effect of smoking on the tested outcome that does not depend on the mediator. The $\mathrm{R}$ code for the mediation analyses is included in Additional file 6, and an example input file is provided in Additional file 7.

The mediation effect of the three-way associations as obtained in our discovery dataset (Additional file 3: Table S6) is provided in Additional file 3: Table S7. Out of the 124 mediation analysis conducted, there was significant mediation effect in 69 of them in the Rotterdam Study (Additional file 3: Table S7). Of these, we were able to replicate the mediating effect of cg01305745 (VKORC1) and cg16448702 (INPP5D) in the association between smoking and PRF1 expression (ILMN_1740633). Also, we identified the mediating effect of cg16448702 (INPP5D) in the association between smoking and OSBPL5 (ILMN_1802151). Furthermore, we replicated the mediation effect of $9 \mathrm{CpGs}$ in the association between smoking and LRRN3 expression (ILMN_1773650 and ILMN_2048591) (Additional file 3: Table S7). Finally, of the replicated three-way associations as shown in Table 4, we were able to replicate the mediation effect of cg03636183 (F2RL3), cg06096336 (PSMD1; HTR2B), cg13708645 (KDM2B), and cg17287155 (AHRR) in the association between smoking and LRRN3 expression (Table 5). We conducted the $\rho$ at which ACME is 0 , to test the models' sensitivity. Here, we obtained $\rho$ 's in the range between -0.1 and -0.5 , and 0.1 and 0.4 . A value of $\rho$ close to 0 indicates that the assumption we made is sensitive to violations [24].

\section{Discussion}

The associations of smoking, gene expression, and DNA methylation with cardio-metabolic traits have been studied independently and reviewed in great detail [11, 25-28]; however, the overlap between epigenetics and transcriptomics in the association between smoking and cardio-metabolic traits has been studied much less. This study investigated the relationship between previously identified smoking-related changes in DNA methylation [6] and gene expression [8], followed by their associations with cardio-metabolic traits within two populationbased cohort studies. In this line, we first showed several significant cis- and trans-eQTM associations between smoking-related CpGs and gene expression probes. Furthermore, we replicated 26 smoking-related CpGs and 19 smoking-related genes (21 probes) associated with cardio-metabolic traits. Moreover, we showed threeway association of TG with two CpGs and two genes (GZMA and CLDND1), and BMI with six CpGs and two genes (PID1 and $L R R N$ ). Finally, our study demonstrated a mediating effect of 4 CpGs (cg03636183, cg06096336, cg13708645, and cg17287155) in the association between smoking and the BMI-related gene LRRN3.

Our results showed a three-way association between TG with the decrease in DNA methylation levels of cg21566642 and the increase in expression levels of CLDND1. In this line, smoking was associated with an increase in the expression of CLDND1 [8] and a decrease in cg21566642 DNA methylation levels [6]; and here, we

Table 5 Mediation effect of DNA methylation and gene expression in the association between smoking and cardiometabolic traits

\begin{tabular}{|c|c|c|c|c|c|c|}
\hline Mediator & Outcome & ACME $(95 \% \mathrm{CI})$ & ADE $(95 \% \mathrm{Cl})$ & $\begin{array}{l}\text { Total effect (95\% } \\
\text { Cl) }\end{array}$ & Prob. Med. $(95 \% \mathrm{Cl})$ & $\begin{array}{l}\rho \text { at which } \\
\text { ACME is } 0^{\text {a }}\end{array}$ \\
\hline cg03636183 (F2RL3) & $\begin{array}{l}\text { ILMN_1773650 } \\
\text { (LRRN3) }\end{array}$ & $\begin{array}{l}0.6835 \\
(0.4731 / 0.8869)\end{array}$ & $\begin{array}{l}1.9603 \\
(1.5832 / 2.3822)\end{array}$ & $\begin{array}{l}2.6438 \\
(2.2907 / 3.0048)\end{array}$ & $\begin{array}{l}0.2585 \\
(0.1767 / 0.3432)\end{array}$ & -0.3 \\
\hline $\begin{array}{l}\text { cg06096336 } \\
\text { (PSMD1;HTR2B) }\end{array}$ & $\begin{array}{l}\text { ILMN_1773650 } \\
\text { (LRRN3) }\end{array}$ & $\begin{array}{l}0.1237 \\
(0.0263 / 0.2396)\end{array}$ & $2.5202(2.1796 / 2.849)$ & $\begin{array}{l}2.6438 \\
(2.2907 / 3.0048)\end{array}$ & $\begin{array}{l}0.0468 \\
(0.0102 / 0.0886)\end{array}$ & -0.4 \\
\hline cg13708645 (KDM2B) & $\begin{array}{l}\text { ILMN_1773650 } \\
\text { (LRRN3) }\end{array}$ & $0.0768(0.025 / 0.1408)$ & $\begin{array}{l}2.5671 \\
(2.2153 / 2.9309)\end{array}$ & $\begin{array}{l}2.6438 \\
(2.2907 / 3.0048)\end{array}$ & $\begin{array}{l}0.0290 \\
(0.0092 / 0.0533)\end{array}$ & -0.1 \\
\hline cg17287155 (AHRR) & $\begin{array}{l}\text { ILMN_1773650 } \\
\text { (LRRN3) }\end{array}$ & $\begin{array}{l}0.6357 \\
(0.4798 / 0.8094)\end{array}$ & $2.0081(1.6771 / 2.333)$ & $\begin{array}{l}2.6438 \\
(2.2907 / 3.0048)\end{array}$ & $\begin{array}{l}0.2405 \\
(0.1835 / 0.3036)\end{array}$ & -0.5 \\
\hline $\begin{array}{l}\text { cg06096336 } \\
\text { (PSMD1;HTR2B) }\end{array}$ & $\begin{array}{l}\text { ILMN_2048591 } \\
\text { (LRRN3) }\end{array}$ & $\begin{array}{l}0.0992 \\
(0.0198 / 0.1915)\end{array}$ & $\begin{array}{l}2.2838 \\
\quad(1.9578 / 2.5975)\end{array}$ & $2.3830(2.0445 / 2.721)$ & $\begin{array}{l}0.0416 \\
(0.0085 / 0.0779)\end{array}$ & -0.3 \\
\hline cg17287155 (AHRR) & $\begin{array}{l}\text { ILMN_2048591 } \\
\text { (LRRN3) }\end{array}$ & $\begin{array}{l}0.5004 \\
(0.3828 / 0.6542)\end{array}$ & $\begin{array}{l}1.8826 \\
(1.5691 / 2.2123)\end{array}$ & $2.3830(2.0445 / 2.721)$ & $\begin{array}{l}0.2100 \\
(0.1603 / 0.2724)\end{array}$ & -0.4 \\
\hline
\end{tabular}

The table shows the results of mediation analysis, in which current smoking is always used as exposure and is adjusted for age and sex

$A C M E$ average causal mediation effect, $A D E$ average direct effect, Prop. Med proportion mediated

a $\rho$ at which ACME is 0 indicates how sensitive our model is to the non-unmeasured confounding assumption 
showed the inverse relation between CLDND1 expression and methylation levels at cg21566642. The expression of CLDND1, a tight junction protein, is shown to be highly increased in human Colon cancer samples and cell lines, and also positively correlated with tumor growth and disease progression [29]. The inverse association between DNA methylation levels at cg21566642 and smoking was previously shown in blood samples with cross-tissue replications in adipose tissue and skin tissue [20]. Additionally, cg21566642 is inversely associated with CVD risk [30], all-cause mortality [31], and with left ventricular mass (LVM) index in young adults [32]. LVM index is an important cardiac remodeling trait that is an intermediate phenotype for heart failure. In line with this, an increased LVM index is associated with high levels of TG [33, 34] and with an increased risk of depressed left ventricular ejection fraction, coronary heart disease, congestive heart failure, and stroke $[35,36]$.

In the three-way association for BMI, we found that smoking is associated with lower BMI, indicating that current smokers are less likely to be obese than never smoker, which has been reported in several previous studies as well [37-39]. Our results further showed that cg03636183 (F2RL3) was positively associated with BMI and negatively associated with the expression of PID1 and LRRN3. Smoking was inversely associated with cg03636183 [6] and positively with PID1 and LRRN3 expression [8]. Here, we found an inverse relation between cg03636183 and expression levels of PID1 and LRRN3. Due to the quality control implemented within the Rotterdam Study gene expression profiling data, gene expression data on F2RL3 was not available. Therefore, we could not test if the association of cg03636183 with PID1 and LRRN3 expression levels was independent or via a downstream effect of F2RL3 expression. Nonetheless, the inverse correlation between DNA methylation levels at cg03636183 and expression of F2RL3 was previously shown [20]. This might indicate that the identified eQTM associations are, at least partly, via $F 2 R L 3$ expression. F2RL3 encodes the protease-activated receptor-4 (PAR-4), a protein expressed in various tissues that introduce platelet activation, intimal hyperplasia, and inflammation [40]. Furthermore, the expression of F2RL3 was associated with metabolic disease risk phenotypes, including a negative association with visceral fat mass and a positive association with total fat mass and android-to-gynoid fat ratio [20]. Additionally, the inverse association between DNA methylation levels at cg03636183 and smoking has been shown in blood samples with cross-tissue replications in adipose and skin tissues [20]. The inverse relation between DNA methylation levels at cg03636183 and TG [41], all-cause mortality [31], lung cancer incidence and mortality [42], as well as total mortality and cardiovascular mortality [43] was also previously identified. Also, a smoking-related decrease in cg03636183 methylation levels appears to increase serum levels of IL-18 [44]. IL-18 promotes the synthesis of IL-6, which stimulates the production of serum CRP $[45,46]$. The increase in IL-18 and IL-6 leads to a higher risk ratio for CHD development [47]. Moreover, the increase in serum CRP concentrations results in increased risk ratios for CHD, ischemic stroke, vascular mortality, and nonvascular mortality [48].

Two of the CpGs, cg26361535 (ZC3H3) and cg25649826 (USP22), for which we found a three-way association with BMI and LRRN3, have been reported to be positively associated with BMI [49]. Both CpGs are cross-tissue replicated in adipose tissue and in isolated adipocytes for obese cases versus normal-weight controls. The association with cg26361535 was in the same direction and for cg25649826 in the opposite direction as obtained in our results [49]. Additionally, both CpGs were positively associated in blood with weight, WHR, glucose, insulin, TG, and CRP, and negatively with HDL. Furthermore, cg26361535 was positively associated with SBP and DBP [49] and all-cause mortality [31].

Finally, we identified a three-way association between BMI, an increase in methylation levels at cg17287155 (AHRR), and LRRN3 expression. Smoking is negatively associated with DNA methylation levels at cg17287155 [6] and, as we replicated here, positively associated with BMI [50]. Notably, in the eQTM look-up we found a ciseQTM for cg17287155 with the expression of EXOC3, instead of with its annotated gene (AHRR). AHRR is a well-studied gene in relation to smoking [5] and is a key regulator of the Xenobiotic metabolism pathway responsible for detoxification of polyaromatic hydrocarbons (PAHs) in tobacco smoke [51, 52]. Nevertheless, EXOC3 overexpression increases insulin-induced glucose uptake in adipocytes [53], indicating a possible link for EXOC3 with CVD-related risk factors. Further research is needed to verify the eQTM-associations for cg17287155 with EXOC3 and its impact on the eQTM-associations identified in the current study.

The identified associations and mediating effects in our study indicate a possible regulatory effect of DNA methylation on the expression levels of genes far from the neighboring methylation site, which so-called transregulatory effect of methylated CpG sites on gene expression [54]. So far, most previous studies have limited their research to the correlation between gene expression and DNA methylation at CpGs located in the nearby regions and in the gene body, or the cis-regulatory effect. In this line, a recent study has shown the trans-regulatory effect of DNA methylation in the associations with gene expression and chronic obstructive pulmonary disease 
[54]. Therefore, future research is needed with a broader methodological approach, including examining possible trans-regulatory effects to gain more insight into the epigenetic regulatory effects in disease studies.

This study has strengths as well as limitations that should be considered when interpreting the results. The main strengths of this study include the availability of DNA methylation data in a large sample of adults from the general population overlapping with transcriptomic and clinical data. Another strength is the use of the largest available EWAS [6] and TWAS [8] to date for selecting the CpGs and genes of interest associated with smoking. A limitation of the current study could be that data on smoking habits are retrieved from questionnaires, which might be underestimating actual smoking levels possibly leading to information bias [55-57]. This self-reporting bias can arise due to several reasons, such as recall bias in which a participant might not remember the true exposure or social desirability bias in which participants deliberately underestimate due to the socially stigmatized nature [57]. However, we expect the underestimation to be primarily quantitative and should not significantly impact the current versus non-smoker categorization we used in this study. Also, the questionnaires used for smoking data-collection did not include information regarding passive smoking, which is a risk factor for CVD [58]. As a result, we were not able to adjust for the passive-smoking effect in our analysis. As these participants are included in the non-smoker group, this might have underestimated the true effect.

Furthermore, due to the nature of the current study we have included the same participants in all mediation analyses and have used the mediator and exposure measurements on the same time-point; therefore, we cannot rule out reverse causality. Another limitation is that DNA methylation and gene expression levels were only measured at baseline; hence, we have no access to premeasurement covariates. Consequently, we could not further adjust our models without risking the adjustment of a mediator, which could explain the $\rho$ values close to 0 we obtained in a subset of our models in the sensitivity analysis. However, we did include additional adjustments (e.g., BMI and relevant medication) in the association analysis between cardio-metabolic traits with DNA methylation and gene expression, indicating the robustness of the identified three-way associations. Also, due to the stringent quality control in the Rotterdam Study, we were not able to test the impact of the cis-eQTM genes in the identified eQTMs. Finally, the use of whole-blood for the quantification of DNA methylation and transcriptomics associated with smoking and cardio-metabolic traits could be a limitation, since DNA methylation and gene expression are tissue-specific. Nonetheless, these data from other tissues are currently not available in the majority of population-based studies including the two participating cohorts in this study.

\section{Conclusions}

In this study, we tested the association of smokingrelated changes in DNA methylation and gene expression with cardio-metabolic traits. We found a three-way association of TG and BMI with CVD-relevant CpG sites and genes. Our results may provide further insight into the possible molecular cascades linking smoking to metabolic risk factors leading to CVD. Further research is warranted to conduct experimental research on the molecular mechanisms of the impact of smoking on cardiovascular disease and its risk factors through changes in DNA methylation and gene expression levels.

\section{Methods \\ Study population}

The discovery data set comprised a total of 1412 participants included in the Rotterdam Study; the design from the Rotterdam Study has been described elsewhere [21]. Briefly, in 1990 all residents of Ommoord, a district in Rotterdam, aged 55 years and older, were invited for participation (RS-I). In 2000, the cohort was extended with participants who had reached the age of 55 years or who had moved into the district (RS-II). An additional group was invited in 2006, from the age of 45 years and older (RS-III). Participants have been re-examined every 3-4 years. In the current study, we used data from the third visit from RS-II (RS-II-3) and the first and second visit of RS-III (RS-III-1 and RS-III-2). In total, DNA methylation measurements of 1412 participants from RSIII-1, RS-II-3, and RS-III-2 were included in our analysis. Additionally, gene expression data were available for 716 participants included in RS-III-1. Smoking information was collected via self-reported questionnaires; additional data collection details are described in Additional file 8.

The replication data comprised a total of 1717 participants included in The Cooperative Health Research in the Region of Augsburg (KORA) study. The KORA study is a series of independent population-based epidemiological surveys and follow-up studies of participants living in the region of Augsburg, Southern Germany. The KORA F4 study, a 7-year follow-up study of the KORA S4 survey (examined 1999-2001), was conducted between 2006 and 2008. The standardized examinations applied in the survey have been described in detail elsewhere [21]. A total of 3080 subjects with ages ranging from 32 to 81 years participated in the examination. In a random subgroup of 1802 KORA F4 subjects, the genome-wide DNA methylation patterns were analyzed as described in Additional file 3 . 
Smoking information was collected via self-reported questionnaires; additional data collection details are described in Additional file 8.

\section{DNA methylation data}

DNA methylation in the Rotterdam Study and KORA study was extracted from whole peripheral blood and DNA methylation measurements were obtained using the Illumina Infinium Human Methylation 450K BeadChip (Illumina Inc, San Diego, CA, USA). The DNA methylation pre-processing procedures are described in Additional file 3. The methylation proportion of a $\mathrm{CpG}$ site was reported as a methylation $\beta$-value in the range of 0 to 1 . Genome coordinates provided by Illumina (GRCh37/hg19) were used to identify independent loci.

In the current study, CpGs of interest were selected using a recent EWAS [6] investigating the association between tobacco smoking and changes in DNA methylation values in the epigenome. In total, $2623 \mathrm{CpG}$ sites were identified as being significantly $\left(P<1 \times 10^{-7}\right)$ differentially methylated between smokers and never smokers. In the Rotterdam Study, 2549 out of the 2623 CpGs passed the quality control and are included in this study (Additional file 3: Table S8).

\section{RNA expression data}

In the Rotterdam Study, RNA was isolated from whole blood and gene expression profiling was performed using the IlluminaHumanHT-12v4 Expression Beadchips (Illumina, San Diego, CA, USA). The expression dataset is available at Gene Expression Omnibus (GEO) public repository under the accession GSE33828: 881 samples are available for analysis. In KORA F4, total RNA was extracted from whole blood and the Illumina Human HT-12 v3 Expression BeadChip (Illumina, San Diego, CA, USA) was used for gene expression profiling [59]. A more detailed description is implemented in Additional file 8.

In the current study, genes of interest were selected using a previous TWAS testing the association between gene expression and current versus never-smoking status [8]. In this TWAS, the meta-analysis was performed on all transcripts with matching gene Entrez IDs. Employing a significance threshold of FDR $<0.05,886$ significant gene Entrez IDs were identified, of which 387 replicated in an independent dataset. Employing the annotation file provided by the Illumina (HumanHT-12_V4), we found 502 gene expression probes to be annotated to these gene Entrez IDs out of which 443 were present in the Rotterdam Study and were included in the current study (Additional file 8: Table S9).

\section{Correlation between DNA methylation and gene expression}

Since DNA methylation and gene expression may affect each other (i.e., eQTMs), we tested the association between 2549 CpGs and 443 gene expression probes linked to smoking in participants who had both methylation and gene expression data available in the Rotterdam Study $(N=716)$. We regressed out age, sex, blood cell counts (fixed effect), and technical covariates (random effect) on the normalized beta-values of the CpGs and separately on the mRNA expression levels using a linear mixed model analysis. The association between the residuals of DNA methylation (independent variable) and gene expression (dependent variable) was examined using a linear regression model. The robust Bonferroni-corrected $P$ value threshold for a significant association was $P<4.4 \times 10^{-8}(0.05 / 443 \times 2549)$.

Additionally, we randomly selected 443 gene expression probes from the IlluminaHumanHT12v4 Expression Beadchips, and 2549 CpGs from the Illumina Human $450 \mathrm{~K}$ array, that were available in the Rotterdam Study. Using the same methods mentioned above, we tested the association between the 2549 smokingrelated CpGs with the 443 randomly selected gene expression probes, and the association between 2549 randomly selected CpGs with the 443 smoking-associated gene expression probes. The chi-square test of independence was used to test possible enrichment for the smoking effect.

\section{Association of DNA methylation and gene expression with cardio-metabolic traits}

We studied the relationship of cardio-metabolic traits with (1) smoking-CpGs associated with at least one smoking-gene probe, and (2) smoking-gene probes associated with at least one smoking-CpG. We included the following cardio-metabolic-related phenotypes: HDL, LDL, TG, serum cholesterol, fasting glucose and insulin levels, SBP, DBP, WHR, and BMI.

First, we tested the association between the smokingrelated CpGs (dependent variable) with the cardio-metabolic traits (exposure variable) using linear mixed effects models (LME4 package in R). The selected covariates in model 1 with fixed effects were age, sex, and cell counts for granulocytes, lymphocytes and monocytes. Array number and position number on array were added in the model as covariates with random effect to correct for batch effect. In model 2, we additionally adjusted for BMI and relevant medication, including for lipid exposures (lipid-lowering medication), for glycemic traits (glucose-lowering medication), for SBP and DBP (lipidlowering medication and anti-hypertensives, diuretics, 
beta-blockers, calcium channel blockers, and RAAS modifying agents).

Second, we tested the association between gene expression (dependent variable) and the cardio-metabolic traits (exposure variable) using linear mixed-effects models (LME4 package in R), adjusting for age, sex, blood cell counts (granulocytes, lymphocytes, and monocytes), RNA quality score and batch effect. In model 2, we additionally adjusted for BMI and relevant medication (as described for DNA methylation).

Third, we combined our EWAS and TWAS results and showed the obtained three-way association; $\mathrm{CpG}$ versus gene expression; cardio-metabolic trait versus $\mathrm{CpG}$; cardio-metabolic trait versus gene expression. For the $\mathrm{CpG}$ versus gene expression, we did a lookup for the identified CpGs to identify possible cis- eQTM associations using data from five Dutch biobanks (BIOS-BBMRI database) in a total of 3841 whole blood samples (https://www. genenetwork.nl/biosqtlbrowser/).

\section{Mediation analysis}

CpGs and gene expression probes associated with each other and associated with the same cardio-metabolic trait were reviewed in three mediation analyses (Fig. 3); (1) the mediation of gene expression in the association between smoking status and the cardio-metabolic trait, (2) the mediation of DNA methylation in the association between smoking status and gene expression changes, and (3) the mediation of DNA methylation in the association between smoking status and the cardio-metabolic trait. In all three analyses, we included the same participants, current versus non-smokers as exposure and all models are corrected for age and sex. In the first analysis, we used the gene expression as potential mediator and the cardio-metabolic trait as outcome. In the second analysis, we used DNA methylation as possible mediator and the gene expression as outcome. In the third analysis, we used DNA methylation as possible mediator and the cardio-metabolic trait as outcome. We used the "mediate" function in the mediation package in $\mathrm{R}$ [60], using the bootstrap method including 1000 simulations and confidence intervals using the $\mathrm{BCa}$ method [61]. The proportion mediated describes the average magnitude of indirect association between smoking status and the gene expression or cardio-metabolic trait attributed through changes in DNA methylation or gene expression relative to the average total association, and it is calculated by dividing the average causal mediation effect by the average total effect [62]. Asymptotic 95\% confidence intervals $(\mathrm{CI})$ were obtained from nonparametric bootstrapping with 1000 iterations. These mediation analyses assumed no additional unmeasured confounding; however, if unobserved variables confound the models, the unmeasured confounding assumption is violated. Therefore, we used the sensitivity analysis included in the mediation package using the "medsens" function conducted by varying the values of $\rho$ and determine the $\rho$ at which ACME is 0 per model. Obtaining a value of $\rho$ close to 0 indicates that the assumption is sensitive to violations, meaning that having a confounder with a higher correlation than the value of $\rho$, the assumption of no additional unmeasured confounding likely does not hold [24].

\section{Replication in the KORA study}

The identified associations in the Rotterdam Study were replicated using the same models in the KORA study. The adjustment for blood cell counts (monocytes, granulocytes, and lymphocytes) was based on Houseman estimates rather than laboratory measurements [63]. Furthermore, principal components were used to adjust for technical covariates rather than plate number and position on array.

\section{Statistical analysis}

All analyses were performed using the statistical package R. The eQTM analysis, and the associations of the cardio-metabolic traits with smoking-related $\mathrm{CpGs}$ and genes were conducted in $\mathrm{R}$ (version 3.2.0) under a Linux operating system, using the "LME4" package (version 1.1-16) and the "parallel" package (version 3.2.0). The mediation analyses were conducted in $\mathrm{R}$ studio Desktop (version 3.2.0) under Windows operating system using the "mediation" package (version 4.4.6.). Data collection and related statistical methods are provided in Additional file 8 .

\section{Supplementary information}

Supplementary information accompanies this paper at https://doi. org/10.1186/s13148-020-00951-0.

Additional file 1. In Additional file 1 (Table S1), we show the expression quantitative trait methylation (eQTM) results per gene expression probe.

Additional file 2. In Additional file 2, we provided the R code we used for obtaining the residuals of the smoking-related CpGs and genes. Also, we provided the $\mathrm{R}$ code used to test the eQTM associations.

Additional file 3. In Additional file 3, we included supplementary Tables S2-S9. In Tables S2-S5, we show the results for the associations between cardio-metabolic traits with DNA methylation model 1 (Table S2) and model 2 (Table S3), and gene expression model 1 (Table S4) and model 2 (Table S5). In Table S6, we show all the three-way associations obtained in the discovery. In Table S7, we show the mediation results for all the three-way associations obtained in the discovery, and the results obtained in the replication. In Table S8, we show the CpGs, and in Table S9, we show the gene expression probes that were included in the current study as markers of interest. 
Additional file 4. In Additional file 4, we provided the R code we used for testing the association between the smoking-related CpGs and the cardio-metabolic traits.

Additional file 5. In Additional file 5, we provided the R code we used for testing the association between the smoking-related gene expression probes and the cardio-metabolic traits.

Additional file 6. In Additional file 6, we provided the R code we used for the mediation analysis.

Additional file 7. In Additional file 7, we provided the input file we used in the discovery phase for mediation analysis.

Additional file 8 In Additional file 8, we included supplementary methods about data collection in the RS and KORA.

\section{Abbreviations}

ACME: Average causal mediation effect; ADE: Average direct effect; BMI: Body mass index; CPACOR: Incorporating control probe adjustment and reduction of global correlation; CVD: Cardiovascular disease; DBP: Diastolic blood pressure; eQTM: Expression quantitative trait methylation; EWAS: Epigenome-wide association study; HDL: High-density lipoprotein; KORA: Cooperative Health Research in the Region of Augsburg; LDL: Low-density lipoprotein; LVM: Left ventricular mass; Prop. med.: Proportion mediated; SBP: Systolic blood pressure; TG: Triglycerides; TWAS: Transcriptome-wide association study; WHR: Waist to hip ratio.

\section{Acknowledgements}

The authors are grateful to the participants of the Rotterdam Study (https ://www.erasmusepidemiology.nl/research/ergo.htm) and the KORA study (https://www.helmholtz-muenchen.de/en/kora/index.html) and also the staff involved in the Rotterdam Study and the KORA study, and the participating general practitioners and pharmacists. The Human Genotyping Facility of the Genetic Laboratory of the Department of Internal Medicine, Erasmus $M C$, the Netherlands generated and managed the generation of the Illumina 450K methylation array data (EWAS data) and the RNA expression data for the Rotterdam Study. We thank Mr. Michael Verbiest, Ms. Mila Jhamai, Ms. Sarah Higgins, Mr. Marijn Verkerk, and Dr. P.R. Mandaviya for their contribution in creating the DNA methylation database. We also thank Ms. Mila Jhamai; Ms. Sarah Higgins; Marjolein Peters, PhD; Mr. Marijn Verkerk; and Jeroen van Rooij, MSc, for their help in creating the RNA array expression database.

\section{Authors' contributions}

SCEM and MG designed this study. JBJM, AGU, AP, HP, CH, HG, SK, MW, MYK, and MK provided data and resources. SCEM performed statistical data analyses in the discovery under supervision of MG. BK performed statistical data analyses in the replication under supervision of MW. SCEM, MM, and MG wrote the first manuscript. All authors read and approved the final manuscript.

\section{Funding}

The Rotterdam Study is funded by Erasmus Medical Center and Erasmus University, Rotterdam, Netherlands Organization for the Health Research and Development (ZonMw), the Research Institute for Diseases in the Elderly (RIDE), the Ministry of Education, Culture and Science, the Ministry for Health, Welfare and Sports, the European Commission (DG XII), and the Municipality of Rotterdam. The establishment of the RS EWAS data was funded by the Genetic Laboratory of the Department of Internal Medicine, Erasmus MC, and by the Netherlands Organization for Scientific Research (NWO; project number 184021007) and made available as a Rainbow Project (RP3; BIOS) of the Biobanking and Biomolecular Research Infrastructure Netherlands (BBMRI-NL). The KORA study was initiated and financed by the Helmholtz Zentrum München - German Research Center for Environmental Health, which is funded by the German Federal Ministry of Education and Research and by the State of Bavaria. Furthermore, KORA research was supported within the Munich Center of Health Sciences (MC-Health), Ludwig-MaximiliansUniversität, Munich, Germany, as part of LMUinnovativ. The German Diabetes Center (DDZ) is supported by the Ministry of Culture and Science of the State of North Rhine-Westphalia and the German Federal Ministry of Health. This study was supported in part by a grant from the German Federal Ministry of Education and Research to the German Center for Diabetes Research (DZD).
The researchers are independent from the funders. The study sponsors had no role in the study design, data collection, data analysis, interpretation of data, and preparation, review or approval of the manuscript.

\section{Availability of data and materials}

The DNA methylation dataset supporting the conclusions of this article can be requested at https://www.epib.nl/research/ergo.htm or contact M. Arfan Ikram (m.a.ikram@erasmusmc.nl) for the Rotterdam Study data. The expression dataset supporting the conclusions of this article is available at GEO (Gene Expression Omnibus) public repository under the accession GSE33828: 881 samples are available for analysis from the Rotterdam Study. The informed consent given by KORA study participants do not cover data posting in public databases. However, data are available upon request from KORA Project Application Self-Service Tool (https://epi.helmholtz-muenchen.de/). Data requests can be submitted online and are subject to approval by the KORA Board.

\section{Ethics approval and consent to participate}

The Rotterdam Study was approved by the institutional review boards of the Medical Ethics Committee of the Erasmus MC (registration number MEC 02.1015) and by the Dutch Ministry of Health, Welfare and Sport (Population Screening Act WBO, license number 1071272-159521-PG). The Rotterdam Study has been entered into the Netherlands National Trial Register (NTR; www.trialregister.nl) and into the WHO International Clinical Trials Registry Platform (ICTRP; www.who.int/ictrp/network/primary/en/) under shared catalogue number NTR6831. The KORA study was approved by the Institutional review board Ethics Committee of the Bavarian Medical Association (Bayrische Landesärztekammer). All participants included in the current study provided written informed consent to participate in the study and to have their information obtained from treating physicians. The experimental methods comply with the Declaration of Helsinki.

\section{Consent for publication}

Not applicable.

\section{Competing interests}

The authors declare that they have no competing interests.

\section{Author details}

${ }_{1}^{1}$ Department of Epidemiology, Erasmus MC University Medical Center Rotterdam, 3015 GB Rotterdam, The Netherlands. ${ }^{2}$ Department of Genetic Identification, Erasmus MC University Medical Center Rotterdam, 3015 GD Rotterdam, The Netherlands. ${ }^{3}$ Research Unit of Molecular Epidemiology, Helmholtz Zentrum München, German Research Center for Environmental Health, 85764 Neuherberg, Germany. ${ }^{4}$ Institute of Epidemiology, Helmholtz Zentrum München, German Research Center for Environmental Health, 85764 Neuherberg, Germany. ${ }^{5}$ Department Internal Medicine, Erasmus MC University Medical Center Rotterdam, 3015 GD Rotterdam, the Netherlands. ${ }^{6}$ German Center for Cardiovascular Research (DZHK), Partner Site Munich Heart Alliance, 80802 Munich, Germany. ${ }^{7}$ Institute for Medical Informatics, Biometrics and Epidemiology, Ludwig-Maximilians-Universität (LMU) Munich, 80333 Munich, Germany. ${ }^{8}$ Institute of Neurogenomics, Helmholtz-Zentrum München-German Research Center for Environmental Health, 85764 Neuherberg, Germany. ${ }^{9}$ Institute for Clinical Diabetology, German Diabetes Center, Leibniz Center for Diabetes Research at Heinrich Heine University Düsseldorf, 40225 Düsseldorf, Germany. ${ }^{10}$ German Center for Diabetes Research (DZD), 85764 Munich-Neuherberg, Germany. ${ }^{11}$ Division of Endocrinology and Diabetology, Medical Faculty, Heinrich Heine University, 40225 Düsseldorf, Germany.

Received: 6 July 2020 Accepted: 13 October 2020

Published online: 22 October 2020

\section{References}

1. WHO. WHO global report on mortality attributale to tobacco. 2012:392.

2. Collaborators GCoD. Global, regional, and national age-sex-specific mortality for 282 causes of death in 195 countries and territories, 1980-2017: a systematic analysis for the Global Burden of Disease Study 2017. Lancet. 2018;392(10159):1736-88. 
3. Sun K, Liu J, Ning G. Active smoking and risk of metabolic syndrome: a meta-analysis of prospective studies. PLoS ONE. 2012;7(10):e47791.

4. Mottillo S, Filion KB, Genest J, Joseph L, Pilote L, Poirier P, et al. The metabolic syndrome and cardiovascular risk a systematic review and meta-analysis. J Am Coll Cardiol. 2010;56(14):1113-32.

5. Kaur G, Begum R, Thota S, Batra S. A systematic review of smoking-related epigenetic alterations. Arch Toxicol. 2019;93(10):2715-40.

6. Joehanes R, Just AC, Marioni RE, Pilling LC, Reynolds LM, Mandaviya PR, et al. Epigenetic signatures of cigarette smoking. Circ Cardiovasc Genet. 2016;9(5):436-47.

7. Zeilinger S, Kühnel B, Klopp N, Baurecht H, Kleinschmidt A, Gieger C, et al. Tobacco smoking leads to extensive genome-wide changes in DNA methylation. PLoS ONE. 2013;8(5):e63812.

8. Huan T, Joehanes R, Schurmann C, Schramm K, Pilling LC, Peters MJ, et al. A whole-blood transcriptome meta-analysis identifies gene expression signatures of cigarette smoking. Hum Mol Genet. 2016;25(21):4611-23.

9. Charlesworth JC, Curran JE, Johnson MP, Goring HH, Dyer TD, Diego VP, et al. Transcriptomic epidemiology of smoking: the effect of smoking on gene expression in lymphocytes. BMC Med Genom. 2010;3:29.

10. Vink JM, Jansen R, Brooks A, Willemsen G, van Grootheest G, de Geus E, et al. Differential gene expression patterns between smokers and nonsmokers: cause or consequence? Addict Biol. 2017;22(2):550-60.

11. Dhana K, Braun KVE, Nano J, Voortman T, Demerath EW, Guan W, et al. An epigenome-wide association study of obesity-related traits. Am J Epidemiol. 2018;187(8):1662-9.

12. Braun KVE, Dhana K, de Vries PS, Voortman T, van Meurs JBJ, Uitterlinden AG, et al. Epigenome-wide association study (EWAS) on lipids: the Rotterdam Study. Clin Epigenet. 2017;9:15.

13. Richard MA, Huan T, Ligthart S, Gondalia R, Jhun MA, Brody JA, et al. DNA methylation analysis identifies loci for blood pressure regulation. Am J Hum Genet. 2017;101(6):888-902.

14. Liu J, Carnero-Montoro E, van Dongen J, Lent S, Nedeljkovic I, Ligthart $\mathrm{S}$, et al. An integrative cross-omics analysis of DNA methylation sites of glucose and insulin homeostasis. Nat Commun. 2019;10(1):2581.

15. Chen BH, Hivert MF, Peters MJ, Pilling LC, Hogan JD, Pham LM, et al. Peripheral blood transcriptomic signatures of fasting glucose and insulin concentrations. Diabetes. 2016;65(12):3794-804.

16. Huan T, Esko T, Peters MJ, Pilling LC, Schramm K, Schurmann C, et al. A meta-analysis of gene expression signatures of blood pressure and hypertension. PLoS Genet. 2015;11(3):e1005035.

17. Ligthart S, Steenaard RV, Peters MJ, van Meurs JB, Sijbrands EJ, Uitterlinden AG, et al. Tobacco smoking is associated with DNA methylation of diabetes susceptibility genes. Diabetologia. 2016;59:998-1006.

18. Steenaard RV, Ligthart S, Stolk L, Peters MJ, van Meurs JB, Uitterlinden AG, et al. Tobacco smoking is associated with methylation of genes related to coronary artery disease. Clin Epigenet. 2015;7(1):54.

19. Zhang Y, Schöttker B, Florath I, Stock C, Butterbach K, Holleczek B, et al. Smoking-associated DNA methylation biomarkers and their predictive value for all-cause and cardiovascular mortality. Environ Health Perspect. 2016;124(1):67-74.

20. Tsai PC, Glastonbury CA, Eliot MN, Bollepalli S, Yet I, Castillo-Fernandez JE, et al. Smoking induces coordinated DNA methylation and gene expression changes in adipose tissue with consequences for metabolic health. Clin Epigenet. 2018;10(1):126.

21. Ikram MA, Brusselle G, Ghanbari M, Goedegebure A, Ikram MK, Kavousi M, et al. Objectives, design and main findings until 2020 from the Rotterdam Study. Eur J Epidemiol. 2020;35(5):483-517.

22. Holle R, Happich M, Löwel H, Wichmann HE, Group MKS. KORA—a research platform for population based health research. Gesundheitswesen. 2005;67(Suppl 1):S19-25.

23. Bonder MJ, Luijk R, Zhernakova DV, Moed M, Deelen P, Vermaat $M$, et al. Disease variants alter transcription factor levels and methylation of their binding sites. Nat Genet. 2017;49(1):131-8.

24. Muthén BO, Muthén LK, Asparouhov T. Regression and mediation analysis using Mplus. Los Angeles: Muthén \& Muthén; 2017.

25. Joehanes $R$, Ying $S$, Huan $T$, Johnson AD, Raghavachari $N$, Wang $R$, et al. Gene expression signatures of coronary heart disease. Arterioscler Thromb Vasc Biol. 2013;33(6):1418-26.

26. Huan T, Zhang B, Wang Z, Joehanes R, Zhu J, Johnson AD, et al. A systems biology framework identifies molecular underpinnings of coronary heart disease. Arterioscler Thromb Vasc Biol. 2013:33(6):1427-34.
27. Burns DM. Epidemiology of smoking-induced cardiovascular disease. Prog Cardiovasc Dis. 2003;46(1):11-29.

28. Muka T, Nano J, Voortman T, Braun KVE, Ligthart S, Stranges S, et al. The role of global and regional DNA methylation and histone modifications in glycemic traits and type 2 diabetes: a systematic review. Nutr Metab Cardiovasc Dis. 2016;26(7):553-66.

29. Dhawan P, Singh AB, Deane NG, No Y, Shiou SR, Schmidt C, et al. Claudin-1 regulates cellular transformation and metastatic behavior in colon cancer. J Clin Invest. 2005;115(7):1765-76.

30. Fernandez-Sanles A, Sayols-Baixeras S, Curcio S, Subirana I, Marrugat J, Elosua R. DNA methylation and age-independent cardiovascular risk, an epigenome-wide approach: the REGICOR Study (REgistre Glroni del COR). Arterioscler Thromb Vasc Biol. 2018;38(3):645-52.

31. Svane AM, Soerensen M, Lund J, Tan Q, Jylhava J, Wang Y, et al. DNA methylation and all-cause mortality in middle-aged and elderly Danish twins. Genes (Basel). 2018;9(2):78

32. Sabogal C, Su S, Tingen M, Kapuku G, Wang X. Cigarette smoking related DNA methylation in peripheral leukocytes and cardiovascular risk in young adults. Int J Cardiol. 2020;306:203-5.

33. Jorgensen PG, Jensen MT, Biering-Sorensen T, Mogelvang R, Galatius $\mathrm{S}$, Fritz-Hansen T, et al. Cholesterol remnants and triglycerides are associated with decreased myocardial function in patients with type 2 diabetes. Cardiovasc Diabetol. 2016;15(1):137.

34. de las Fuentes L, Waggoner AD, Brown AL, Davila-Roman VG. Plasma triglyceride level is an independent predictor of altered left ventricular relaxation. J Am Soc Echocardiogr. 2005;18(12):1285-91.

35. Drazner MH, Rame JE, Marino EK, Gottdiener JS, Kitzman DW, Gardin JM, et al. Increased left ventricular mass is a risk factor for the development of a depressed left ventricular ejection fraction within five years: the Cardiovascular Health Study. J Am Coll Cardiol. 2004:43(12):2207-15.

36. Gardin JM, McClelland R, Kitzman D, Lima JA, Bommer W, Klopfenstein $\mathrm{HS}$, et al. M-mode echocardiographic predictors of six- to seven-year incidence of coronary heart disease, stroke, congestive heart failure, and mortality in an elderly cohort (the Cardiovascular Health Study). Am J Cardiol. 2001:87(9):1051-7.

37. Molarius A, Seidell JC, Kuulasmaa K, Dobson AJ, Sans S. Smoking and relative body weight: an international perspective from the WHO MONICA Project. J Epidemiol Community Health. 1997;51 (3):252-60.

38. Shimokata $\mathrm{H}$, Muller DC, Andres R. Studies in the distribution of body fat. III. Effects of cigarette smoking. JAMA. 1989;261 (8):1169-73.

39. Dare S, Mackay DF, Pell JP. Relationship between smoking and obesity: a cross-sectional study of 499,504 middle-aged adults in the UK general population. PLoS ONE. 2015;10(4):e0123579.

40. Leger AJ, Covic L, Kuliopulos A. Protease-activated receptors in cardiovascular diseases. Circulation. 2006;114(10):1070-7.

41. Dekkers KF, van Iterson M, Slieker RC, Moed MH, Bonder MJ, van Galen $\mathrm{M}$, et al. Blood lipids influence DNA methylation in circulating cells. Genome Biol. 2016;17(1):138.

42. Zhang Y, Schottker B, Ordonez-Mena J, Holleczek B, Yang R, Burwinkel $B$, et al. F2RL3 methylation, lung cancer incidence and mortality. Int J Cancer. 2015;137(7):1739-48.

43. Zhang Y, Yang R, Burwinkel B, Breitling LP, Holleczek B, Schottker B, et al. F2RL3 methylation in blood DNA is a strong predictor of mortality. Int J Epidemiol. 2014;43(4):1215-25.

44. Jhun MA, Smith JA, Ware EB, Kardia SLR, Mosley TH Jr, Turner ST, et al. Modeling the causal role of DNA methylation in the association between cigarette smoking and inflammation in African Americans: a 2-Step Epigenetic Mendelian Randomization Study. Am J Epidemiol. 2017:186(10):1149-58

45. Gerdes N, Sukhova GK, Libby P, Reynolds RS, Young JL, Schonbeck U. Expression of interleukin (IL)-18 and functional IL-18 receptor on human vascular endothelial cells, smooth muscle cells, and macrophages: implications for atherogenesis. J Exp Med. 2002;195(2):245-57.

46. Jones SA, Novick D, Horiuchi S, Yamamoto N, Szalai AJ, Fuller GM. C-reactive protein: a physiological activator of interleukin 6 receptor shedding. J Exp Med. 1999;189(3):599-604.

47. Kaptoge S, Seshasai SR, Gao P, Freitag DF, Butterworth AS, Borglykke A, et al. Inflammatory cytokines and risk of coronary heart disease: new prospective study and updated meta-analysis. Eur Heart J. 2014;35(9):578-89. 
48. Emerging Risk Factors C, Kaptoge S, Di Angelantonio E, Lowe G, Pepys MB, Thompson SG, et al. C-reactive protein concentration and risk of coronary heart disease, stroke, and mortality: an individual participant meta-analysis. Lancet. 2010;375(9709):132-40.

49. Wahl S, Drong A, Lehne B, Loh M, Scott WR, Kunze S, et al. Epigenomewide association study of body mass index, and the adverse outcomes of adiposity. Nature. 2017:541(7635):81-6.

50. Aslibekyan S, Demerath EW, Mendelson M, Zhi D, Guan W, Liang L, et al. Epigenome-wide study identifies novel methylation loci associated with body mass index and waist circumference. Obesity (Silver Spring). 2015;23(7):1493-501.

51. Larigot $L$, Juricek L, Dairou J, Coumoul X. AhR signaling pathways and regulatory functions. Biochim Open. 2018;7:1-9.

52. Vu AT, Taylor KM, Holman MR, Ding YS, Hearn B, Watson CH. Polycyclic aromatic hydrocarbons in the mainstream smoke of popular U.S. cigarettes. Chem Res Toxicol. 2015;28(8):1616-26.

53. Ewart MA, Clarke M, Kane S, Chamberlain LH, Gould GW. Evidence for a role of the exocyst in insulin-stimulated Glut4 trafficking in 3T3-L1 adipocytes. J Biol Chem. 2005;280(5):3812-6.

54. Yoo S, Takikawa S, Geraghty P, Argmann C, Campbell J, Lin L, et al. Integrative analysis of DNA methylation and gene expression data identifies EPAS1 as a key regulator of COPD. PLoS Genet. 2015;11(1):e1004898.

55. Connor Gorber S, Schofield-Hurwitz S, Hardt J, Levasseur G, Tremblay M. The accuracy of self-reported smoking: a systematic review of the relationship between self-reported and cotinine-assessed smoking status. Nicotine Tob Res. 2009;11(1):12-24.
56. Tripepi G, Jager KJ, Dekker FW, Zoccali C. Selection bias and information bias in clinical research. Nephron Clin Pract. 2010;115(2):c94-9.

57. Althubaiti A. Information bias in health research: definition, pitfalls, and adjustment methods. J Multidiscip Healthc. 2016;9:211-7.

58. Khoramdad M, Vahedian-Azimi A, Karimi L, Rahimi-Bashar F, Amini $\mathrm{H}$, Sahebkar A. Association between passive smoking and cardiovascular disease: a systematic review and meta-analysis. IUBMB Life. 2020;72(4):677-86.

59. Schurmann C, Heim K, Schillert A, Blankenberg S, Carstensen M, Dörr M et al. Analyzing illumina gene expression microarray data from different tissues: methodological aspects of data analysis in the metaxpress consortium. PLOS ONE. 2012;7(12):e50938.

60. Tingley D, Yamamoto T, Hirose K, Keele L, Imai K. Mediation: R package for causal mediation analysis. J Stat Softw. 2014;59(5):1-38.

61. DiCiccio TJ, Efron B. Bootstrap confidence intervals. Stat Sci. 1996;11(3):189-228.

62. Imai K, Keele L, Tingley D. A general approach to causal mediation analysis. Psychol Methods. 2010;15(4):309-34.

63. Houseman EA, Accomando WP, Koestler DC, Christensen BC, Marsit CJ, Nelson $\mathrm{HH}$, et al. DNA methylation arrays as surrogate measures of cell mixture distribution. BMC Bioinform. 2012;13:86.

\section{Publisher's Note}

Springer Nature remains neutral with regard to jurisdictional claims in published maps and institutional affiliations.
Ready to submit your research? Choose BMC and benefit from:

- fast, convenient online submission

- thorough peer review by experienced researchers in your field

- rapid publication on acceptance

- support for research data, including large and complex data types

- gold Open Access which fosters wider collaboration and increased citations

- maximum visibility for your research: over 100M website views per year

At BMC, research is always in progress.

Learn more biomedcentral.com/submissions 